\title{
Ticks and associated pathogens in dogs from Greece
}

\author{
Maria Stefania Latrofa', Athanasios Angelou², Alessio Giannelli ${ }^{1}$, Giada Annoscia', Silvia Ravagnan², \\ Filipe Dantas-Torres ${ }^{1,4}$, Gioia Capelli ${ }^{3}$, Lenaig Halos ${ }^{5}$, Frederic Beugnet ${ }^{5}$, Elias Papadopoulos ${ }^{2}$ \\ and Domenico Otranto ${ }^{1 *}$
}

\begin{abstract}
Background: With the aim to assess the occurrence of hard ticks and the pathogens they may carry in dogs from Greece, ixodid specimens $(n=757)$ were collected from 310 animals living in six provinces across the Greek peninsula. All ticks were morphologically identified, and genomic DNA was extracted from 344 (45.5\%) representative specimens, according to their species, engorgement status and sampling area. The occurrence of Anaplasma spp., Ehrlichia spp., Hepatozoon spp., Rickettsia spp., Babesia spp., Theileria spp. and Cercopithifilaria spp. was assessed by conventional and quantitative real-time PCR.

Results: Overall, 150 dogs (48.4\%) were infested by ticks, with Rhipicephalus sanguineus (sensu lato) being the most prevalent (70.1\%), followed by Haemaphysalis parva (14.7\%), Rhipicephalus turanicus (11.4\%), and Haemaphysalis concinna (2.4\%). Out of 344 specimens molecularly examined, 41 (11.1\%) were positive for at least one microorganism (i.e. 5.5\% for Cercopithifilaria bainae, 2.9\% for Hepatozoon canis, 1.7\% for Rickettsia hoogstraalii, $1.2 \%$ for Hepatozoon felis, $0.6 \%$ for Rickettsia massiliae, $0.6 \%$ for Theileria ovis, $0.3 \%$ for Anaplasma platys and $0.3 \%$ for Coxiella like-endosymbiont).

Conclusions: The results of this study show that different tick species parasitize dogs in Greece, carrying a range of microorganisms potentially pathogenic for dogs and humans. Consequently, control strategies against ticks are of great importance to prevent the risk of tick-borne diseases. The relationship between ticks infesting dogs and associated microorganisms is described according to collection site and dog lifestyle.
\end{abstract}

Keywords: Ticks, Tick-borne pathogens, Dogs, Greece, PCR, qPCR, TBDs

\section{Background}

Ticks represent a major threat to domestic and wild animals worldwide due to blood depletion, inoculation of toxins and allergens and, importantly, pathogen transmission [1]. A range of viruses, bacteria and protozoa causing tick-borne diseases (TBDs) induces economic losses in livestock production [2] and puts at risk the health of companion animals [3, 4]. In addition, several tick-borne pathogens are of zoonotic concern and their transmission to humans is related to a number of driving factors, including the presence of proper vectors and hosts [5-8]. The distribution of ticks and their vectored

\footnotetext{
*Correspondence: domenico.otranto@uniba.it

'Dipartimento di Medicina Veterinaria, Università degli Studi di Bari,

Valenzano, Bari, Italy

Full list of author information is available at the end of the article
}

pathogens is affected by a plethora of biological and environmental determinants, including climate changes, deforestation, and urbanisation, which may together favour the spreading and establishment of selected vectors into previously free areas [9-11]. The scientific knowledge on the ecology of different tick species becomes, therefore, pivotal to assess the risk factors for pathogen transmission.

The Mediterranean basin provides an optimal environment for the development of a number of tick species [12-14]. In Greece, for instance, a range of ixodid species has been reported in domestic animals and humans, including Rhipicephalus sanguineus (sensu lato), Rhipicephalus turanicus, Rhipicephalus bursa, Hyalomma marginatum, Hyalomma rufipes, Hyalomma turanicum, Hyalomma excavatum, Hyalomma scupense, 
Ixodes ricinus, Ixodes gibbosus, Ixodes hexagonus, Haemaphysalis inermis, Haemaphysalis punctata, Haemaphysalis sulcata, Haemaphysalis parva, Dermacentor marginatus and Amblyomma variegatum [15-20].

While most of the studies carried out have focused their attention on the ixodid fauna of livestock, only a few have been performed on dogs, mainly in the northern part of the Greek peninsula [16, 17]. Accordingly, selected canine tick-borne pathogens (e.g. Hepatozoon canis, Anaplasma spp., Rickettsia spp. and Cercopithifilaria spp.) have also been detected [21-23], although there is no clear association between tick species and their pathogens.

In order to fill this gap in knowledge, this study aimed to investigate the distribution of hard ticks and carried pathogens in dogs living under different conditions across Greece.

\section{Methods}

\section{Tick collection and identification}

From May to August 2015, tick specimens were collected on domestic dogs living in six provinces across
Greece (Fig. 1, Table 1), specifically from southern (Corinth, site A; Athens, site B), central (Larisa, site C) and northern regions (i.e. Xanthi, site D; Thessaloniki, site E; Alexandroupoli, site F). Ticks were sampled on animals from rural areas, municipal shelters, temporary kennels, indoor environments, or in hospitalised animals (Table 1).

All ticks were preserved in $70 \%$ ethanol and categorised according to their gender and developing stages. Specimens were morphologically identified at species level using morphological keys [12, 24, 25].

\section{Pathogen molecular diagnosis}

Genomic DNA was extracted from a representative number of tick specimens, according to their species, engorgement status and sampling area. Ticks were cut into small pieces using sterile scalpels, homogenized in $300 \mu \mathrm{l}$ of DNA extraction buffer $(20 \mathrm{mM}$ Tris- $\mathrm{HCl}$ $\mathrm{pH}$ 8; $100 \mathrm{mM}$ EDTA and 1\% SDS, $400 \mu \mathrm{g}$ proteinase $\mathrm{K})$, and incubated overnight at $37{ }^{\circ} \mathrm{C}$. Protein was precipitated using $50 \mu \mathrm{l}$ of $5 \mathrm{M}$ potassium acetate, before samples were stored on ice for $10 \mathrm{~min}$ and centrifuged

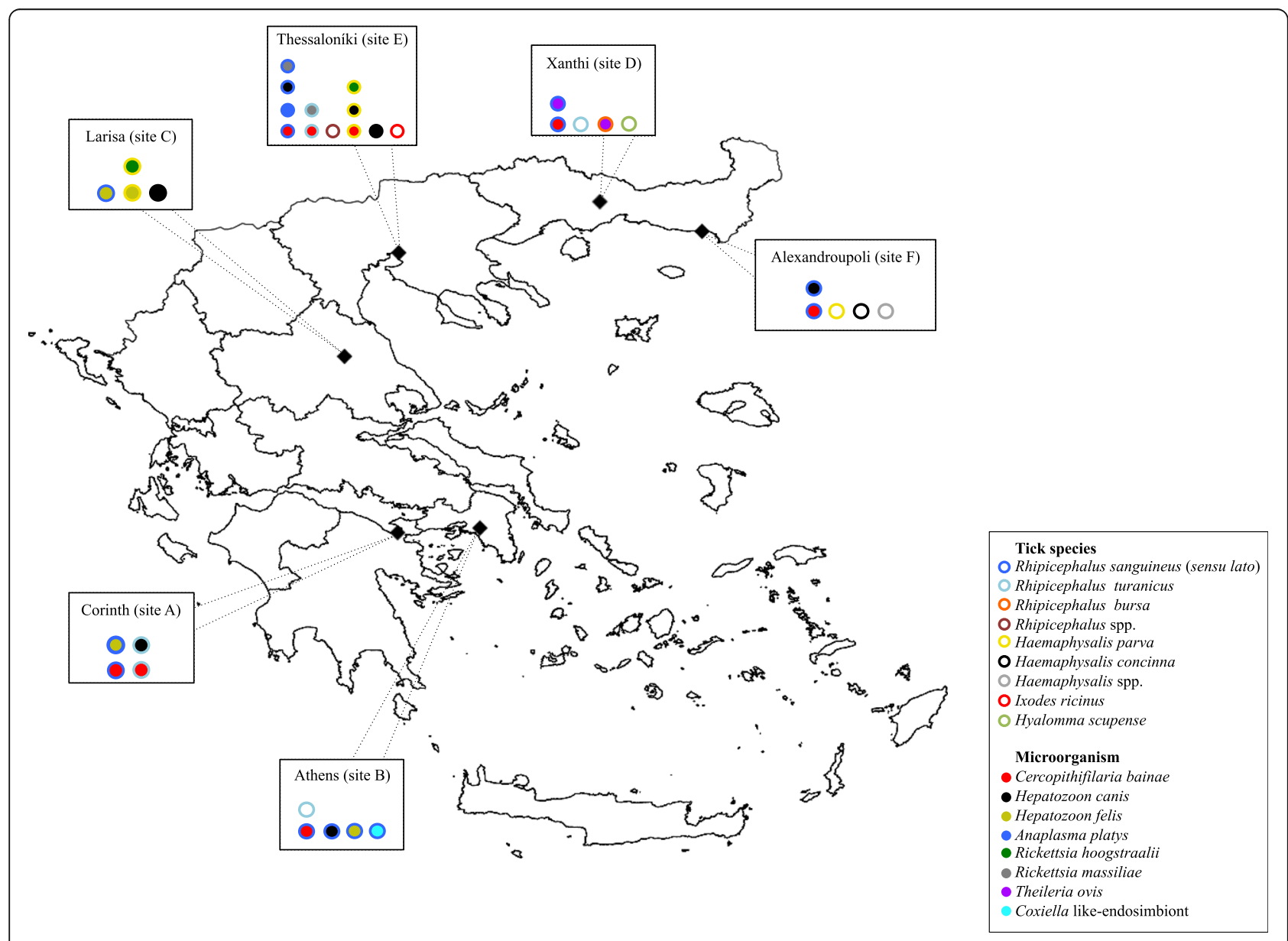

Fig. 1 Distribution of tick species and their positivity for microorganisms according to the sampling site 


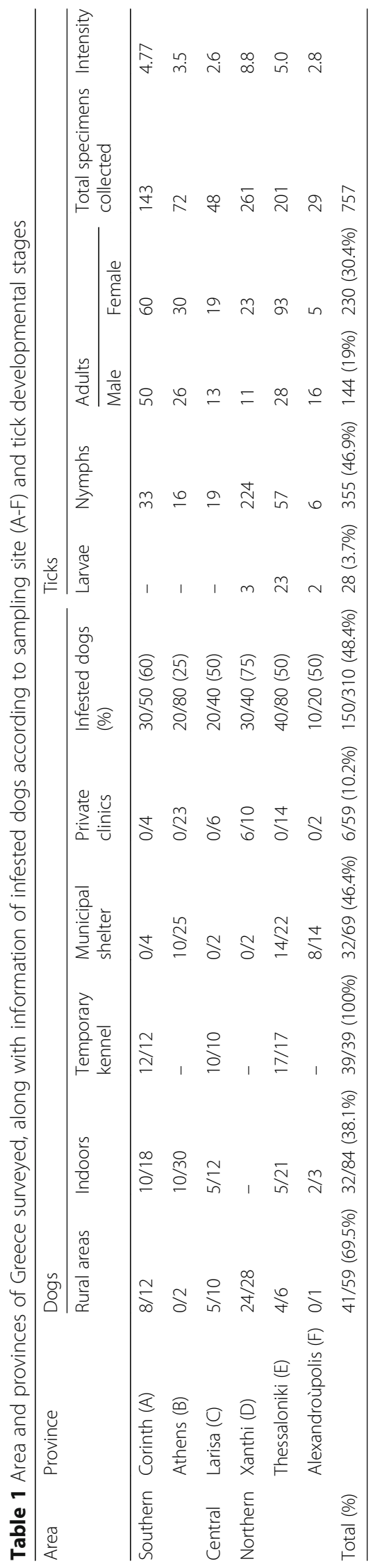


at $13,000 \times g$ for $5 \mathrm{~min}$. The DNA pellet was precipitated using $300 \mu \mathrm{l}$ of $100 \%$ isopropanol followed by centrifugation at $13,000 \times g$ for $5 \mathrm{~min}$ and a final wash with $300 \mu \mathrm{l}$ of $70 \%$ ethanol and centrifugation at $13,000 \times \mathrm{g}$ for $5 \mathrm{~min}$. Pellets were air dried and resuspended in $50 \mu \mathrm{l}$ TE (10 mM Tris-HCl, 1 mM EDTA pH 8).

Target sequences of Anaplasma/Ehrlichia spp., Babesia/Theileria spp. and Rickettsia spp. were detected by quantitative real-time PCR assays (qPCR), as described previously [26-28]. In addition, DNA of canine filarioids and Hepatozoon spp. was detected by conventional PCR amplification of partial cytochrome $c$ oxidase subunit 1 (cox1, $690 \mathrm{bp})$ and 18S rRNA ( 670 bp) genes, respectively, using primers and cycling protocols described previously [29, 30].

PCR products were examined on $2 \%$ agarose gels stained with GelRed (VWR International PBI, Milano, Italy) and visualised on a GelLogic 100 gel documentation system (Kodak, New York, USA). The amplicons were purified and sequenced in both directions using the same primers used for PCR and qPCR, employing the Big Dye Terminator v.3.1 chemistry in a 3130 genetic analyser (Applied Biosystems, California, USA). Sequences were aligned using the ClustalW program [31] and compared with those available in GenBank by Basic Local Alignment Search Tool (BLAST - http://blast.ncbi .nlm.nih.gov/Blast.cgi).

\section{Statistical analysis}

Prevalence (proportion of hosts infested by ticks and of tick species positive for a given pathogen) and tick infestation burden (arithmetic mean count of ticks on each infested hosts) were assessed. For prevalence rates $>5 \%$, Fisher's exact test was used to compare the prevalence of infection among sampling areas, and among dog keeping conditions. Differences were considered significant when $P<0.05$. Statistical analyses were performed using BioEstat 5.0.

\section{Results}

Of the 310 dogs examined, 150 (48.4\%) harboured ticks, with the infestation prevalence varying according to sampling sites and dog keeping conditions (Table 1). Out of 757 ticks collected, $374(49.4 \%)$ were adults (i.e. 230 females and 144 males), 355 (46.9\%) nymphs and 28 (3.7\%) larvae.

Overall, four tick genera and seven species were identified (Table 2), with the most representative tick species being $R$. sanguineus (s.l.) (70.1\%), followed by $H$. parva (14.7\%), $R$. turanicus (11.4\%) and $H$. concinna $(2.4 \%)$ (Fig. 1, Table 2). Mixed infestations were recorded in 10 dogs $(6.7 \%)$, three of which harboured $H$. parva and $H$. concinna, two $H$. parva and $R$. sanguineus (s.l.) or $H$. parva and I. ricinus, and one each Hyalomma scupense and $R$. bursa, $R$. sanguineus (s.l.) and $R$. turanicus. One dog was simultaneously infested by $H$. parva, $R$. sanguineus (s.l.) and I. ricinus.

Though not statistically significant $(P>0.05)$, the tick burden varied according to dog type (i.e. dogs sheltered in temporary kennels or living in rural areas were more often infested than those referred to private veterinary clinics or housed indoor) and the sampling sites. Dogs from site D (northern Greece) harboured more ticks than those from sites $\mathrm{B}$ and $\mathrm{C}$ (southern and central Greece) (Table 1). While R. sanguineus (s.l.) was found in all the sampling areas, $R$. turanicus and $H$. parva were not detected in site $\mathrm{C}$ and sites $\mathrm{A}, \mathrm{B}$ or $\mathrm{D}$, respectively (Table 2). Specimens of $I$. ricinus, H. scupense and $R$. bursa were found only in northern regions (Fig. 1, Table 2). Rhipicephalus sanguineus (s.l.), R. turanicus, $R$. bursa and $H$. scupense were thoroughly collected from dogs living in rural areas, municipal shelter, and referred to private clinics, whereas Haemaphysalis spp. were mainly found on animals from temporary kennels (Table 2).

Out of 344 specimens analysed, 41 (11.1\%) were positive for at least one microorganism based on PCR (Table 2 ), with the largest number of positives being detected in the northern regions (Fig. 1). Nineteen ticks (5.5\%; nine females, two larvae, and eight nymphs) were positive for Cercopithifilaria bainae, 10 (2.9\%; two males, four females, one larva, and three nymphs) for $H$. canis and six (1.7\%; one male and five females) for Rickettsia hoogstraalii. Other microorganisms were detected less frequently, such as Hepatozoon felis (1.2\%; one male, one female, and two nymphs), Rickettsia massiliae (0.6\%; one larva and one nymph), Theileria ovis ( $0.6 \%$; two males), A. platys ( $0.3 \%$; one nymph) and for a Coxiella-likeendosymbiont ( $0.3 \%$; one female) (Table 2 , Fig. 1$)$. Co-infections with multiple microorganisms were detected in six specimens. In particular, $C$. bainae was detected in combination with $H$. felis or $H$. canis or $R$. massiliae in $R$. sanguineus (s.l.), and with $H$. canis in $R$. turanicus. Rickettsia hoogstraalii was simultaneously diagnosed with $H$. felis or $H$. canis and $C$. bainae in $H$. parva. Associations between tick developmental stages, dog lifestyles, collection site and microorganisms are reported in Table 2, and none of the parameters evaluated was statistically significant $(P>0.05)$.

BLAST analysis confirmed the identification of the detected microorganisms with the highest nucleotide identity of $98-100 \%$ with the sequences available in the GenBank database (Accession numbers: KF270686, AJ537512, KC138534, KJ605146, KJ605147, EF201806, KX273858, KJ663754, EF629536).

\section{Discussion}

Data from this study indicate that dogs from Greece are exposed to different tick species and, potentially, to 


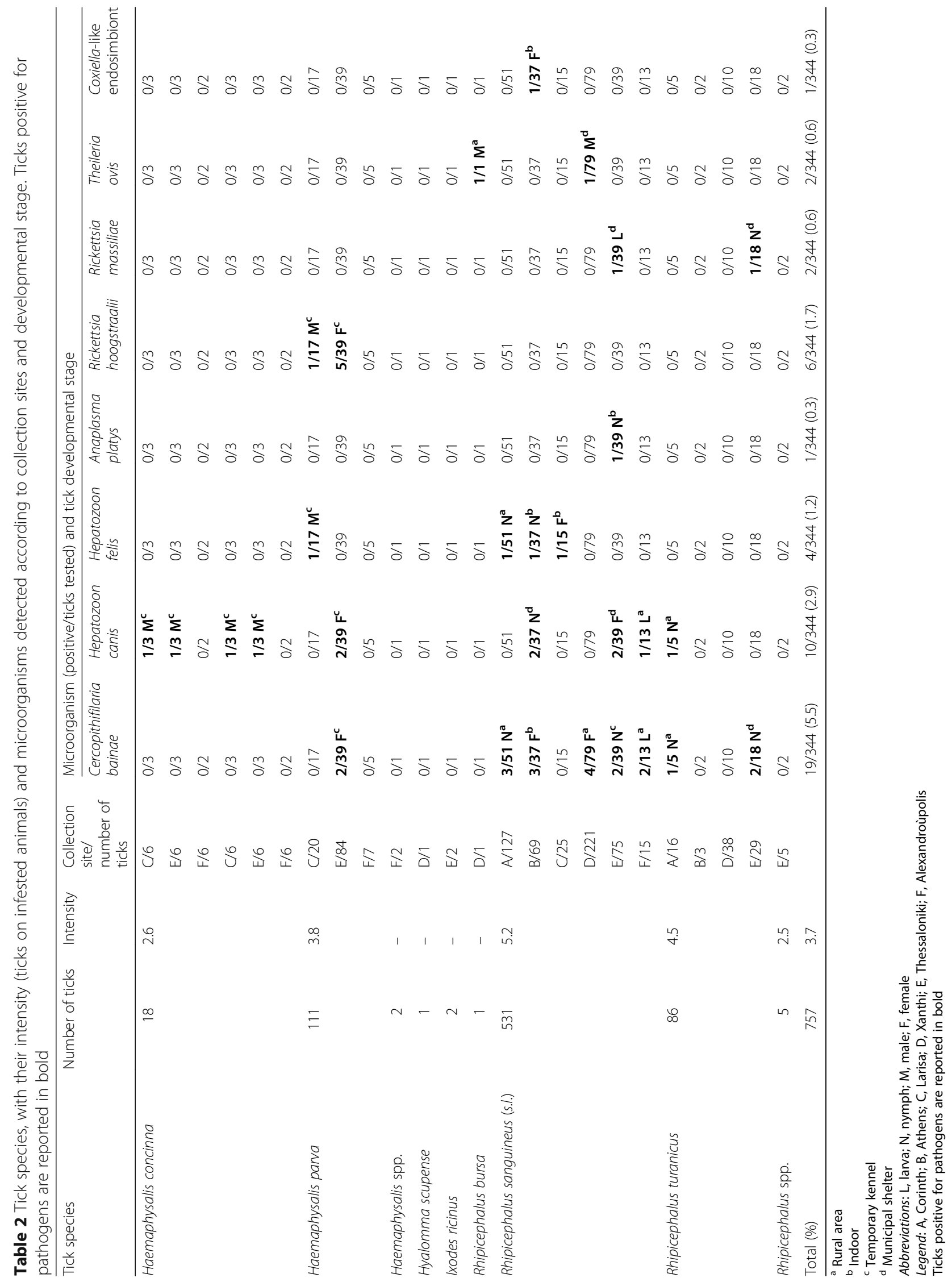


several tick-borne pathogens, whose occurrence is not strictly influenced by the conditions in which dogs live. Nonetheless, the finding of a higher tick burden in animals from kennels, rural areas or municipal shelters compared to those kept indoor is presumably related to the frequency of treatment against ectoparasites, which is performed more frequently in pet than in shepherd or kennelled dogs [32].

Overall, the collection of different tick species in each of the geographical areas confirms the existence of a marked ixodid diversity in the Greek peninsula [16, 20, 22] with a higher number of ticks sampled in northern areas bordering continental Europe (i.e. Macedonia, Turkey and Albania) [16, 32, 33] than southern regions $[16,20]$.

Rhipicephalus sanguineus (s.l.) was the most prevalent species throughout Greece, most likely due to its strict affiliation to canids [25], and/or its ability to survive in a large array of environmental conditions [13, 16, 34-36]. Conversely, the finding of $R$. turanicus on dogs is probably related to its adaptability to several vertebrate animals, including goats and sheep [25], which have a major role in the economy of this country. Along with $R$. bursa and $H$. scupense, $R$. turanicus can often be detected on livestock in the northern regions of Greece [20], where they often parasitize dogs [16]. Haemaphysalis parva and $H$. concinna usually parasitize birds as larvae and nymphs, and herbivores as adults [24]. Finding these species on dogs was likely due to the location of animal shelters, close to forested, meadow and rural habitats [37].

Amongst the microorganisms detected, the filarioid $C$. bainae was the most common, being found in $R$. sanguineus (s.l.), as previously reported [22]. The detection of C. bainae in $H$. parva probably occurred during the ingestion of skin-dwelling microfilariae during the tick blood meal. Nonetheless, considering that the same tick species was found positive for $H$. canis and $H$. felis, its implication as a vector for these pathogens cannot be ruled out. Though $H$. felis has been detected in $R$. sanguineus (s.l.) $[38,39]$, the vector of this protozoon remains unknown, whereas $H$. canis has been so far been detected in a number of other tick species, including Haemphysalis spp. and $R$. turanicus $[40,41]$. In the current study, $H$. parva specimens were positive for $R$. hoogstraalii, adding new scientific information to knowledge on this Rickettsia species. Rickettsia hoogstraalii was originally isolated from $H$. sulcata from sheep and goats in Croatia [42], H. punctata and H. sulcata from Spain [43] and, in the same tick species from foxes in Cyprus [44]. Rickettsia massiliae was here found in $R$. sanguineus (s.l.) and $R$. turanicus collected from dogs living in municipal shelters in northern Greece, close to the Turkish boundaries. This finding is not surprising when considering that the transstadial and transovarial transmission of $R$. massiliae has been described in both Rhipicephalus species [45]. Besides the current report, $R$. massiliae has been detected in $R$. sanguineus (s.l.) and $R$. turanicus from Greece and other countries (e.g. Spain, Portugal, Switzerland, France, Algeria, Morocco, Israel and Italy) [6, 46], as well as in Rhipicephalus mushamae, Rhipicephalus lunulatus, Rhipicephalus sulcatus and Rhipicephalus guilhoni [6, 25].

Remarkably, $R$. massiliae has not yet been isolated from humans in Greece, but its detection in Rhipicephalus spp. ticks suggest that the risk for human infections is probably underestimated $[46,47]$. The absence of $E$. canis and Babesia vogeli positive ticks in this study was surprising as both pathogens are transmitted by $R$. sanguineus (s.l.) ticks [48, 49], and could be explained by their transitory parasitaemia and by the number of ticks examined.

\section{Conclusions}

The results of this study show that different tick species parasitize dogs in Greece, carrying a range of microorganisms potentially pathogenic for dogs and humans. As such, control strategies against ticks are of great importance to prevent the risk of TBDs.

\section{Abbreviations \\ cox1: Cytochrome $c$ oxidase subunit 1; qPCR: quantitative real-time PCR as- says; TBDs: Tick-borne diseases \\ Acknowledgements \\ Not applicable. \\ Funding \\ This study was conducted under the frame of the EurNegVec COST Action TD1303 and supported by Merial SAS (France).}

Availability of data and materials

All data supporting the conclusions of this article are included within the article.

Authors' contributions

EP and DO conceived the study. AG and AA performed the morphological identification of ticks. MSL, AA, GA, SR and GC performed the molecular identification of pathogens. MSL, AG and DO wrote the first draft of the manuscript. FDT, LH, EP and FB reviewed the manuscript. All authors read and approved the final manuscript.

\section{Competing interests}

The authors declare that they have no competing interest.

Consent for publication

Not applicable.

Ethics approval

Informed consent and agreement were obtained from dog owners or veterinarians before sampling ticks. The examination of animals was conducted with regards to their welfare.

\section{Publisher's Note}

Springer Nature remains neutral with regard to jurisdictional claims in published maps and institutional affiliations. 


\section{Author details}

'Dipartimento di Medicina Veterinaria, Università degli Studi di Bari, Valenzano, Bari, Italy. ${ }^{2}$ School of Veterinary Medicine, Faculty of Health Sciences, Aristotle University of Thessaloniki, Thessaloniki, Greece. ${ }^{3}$ Istituto Zooprofilattico Sperimentale delle Venezie, Legnaro, Padua, Italy. ${ }^{4}$ Departamento de Imunologia, Instituto de Pesquisas Aggeu Magalhães (Fiocruz-PE), Recife, Pernambuco, Brazil. ${ }^{5}$ Merial SAS (Boehringer Ingelheim), 29 avenue Tony Garnier, Lyon, France.

\section{Received: 4 April 2017 Accepted: 30 May 2017}

\section{Published online: 23 June 2017}

\section{References}

1. Bowman AS, Nuttall PA. Ticks: biology, disease and control. United Kingdom: Cambridge University Press; 2008.

2. Grisi L, Leite RC, Martins JR, Barros AT, Andreotti R, Cançado PH, et al. Reassessment of the potential economic impact of cattle parasites in Brazil. Rev Bras Parasitol Vet. 2014;23:150-6.

3. Dantas-Torres F, Chomel BB, Otranto D. Ticks and tick-borne diseases: a one health perspective. Trends Parasitol. 2012;28:437-46.

4. Baneth G, Thamsborg SM, Otranto D, Guillot J, Blaga R, Deplazes P, et al. Major parasitic zoonoses associated with dogs and cats in Europe. J Comp Pathol. 2016;155:S54-74.

5. Jongejan F, Uilenberg G. The global importance of ticks. Parasitology. 2004:129:S3-14

6. Oteo JA, Portillo A. Tick-borne rickettsioses in Europe. Ticks Tick Borne Dis. 2012:3:271-8.

7. McCoy KD, Léger $E$, Dietrich M. Host specialization in ticks and transmission of tick-borne diseases: a review. Front Cell Infect Microbiol. 2013;3:57.

8. Dantas-Torres F. Climate change, biodiversity, ticks and tick-borne diseases: the butterfly effect. Int J Parasitol Parasites Wildl. 2015:4:452-61.

9. Colwell DD, Dantas-Torres F, Otranto D. Vector-borne parasitic zoonoses: emerging scenarios and new perspectives. Vet Parasitol. 2011;182:14-21.

10. Estrada-Peña A, Ayllón N, de la Fuente J. Impact of climate trends on tickborne pathogen transmission. Front Physiol. 2012;3:64.

11. Ostfeld RS, Brunner JL. Climate change and Ixodes tick-borne diseases of humans. Philos Trans R Soc Lond B Biol Sci. 2015;370(1665)

12. Estrada-Peña A, Bouattour A, Camicas JL, Walker AR. Ticks of domestic animals in the Mediterranean region. A guide of identification of species. Zaragoza: University of Zaragoza Press; 2004. p. 131.

13. Dantas-Torres F, Latrofa MS, Annoscia G, Giannelli A, Parisi A, Otranto D. Morphological and genetic diversity of Rhipicephalus sanguineus sensu lato from the new and old worlds. Parasit Vectors. 2013:6:213.

14. Dantas-Torres F, Otranto D. Species diversity and abundance of ticks in three habitats in southern Italy. Ticks Tick Borne Dis. 2013:4:251-25.

15. Papazahariadou MG, Papdopoulos EG, Himonas CA. Seasonal activity of ixodid ticks on goats in northern Greece. Vet Rec. 1995;136:585-8.

16. Papadopoulos B, Morel PC, Aeschlimann A. Ticks of domestic animals in the Macedonia region of Greece. Vet Parasitol. 1996:63:25-40.

17. Papazahariadou MG, Saridomichelakis MN, Koutinas AF, Papadopoulos EG, Leontides L. Tick infestation of dogs in Thessaloniki, northern Greece. Med Vet Entomol. 2003;17:110-3.

18. Pavlidou V, Gerou S, Kahrimanidou M, Papa A. Ticks infesting domestic animals in northern Greece. Exp Appl Acarol. 2008:45:195-8.

19. Papa A, Chaligiannis I, Xanthopoulou K, Papaioakim M, Papanastasiou S, Sotiraki S. Ticks parasitizing humans in Greece. Vector Borne Zoonotic Dis. 2011;11:539-42

20. Chaligiannis I, Musella V, Rinaldi L, Cringoli G, de la Fuente J, Papa A, et al. Species diversity and spatial distribution of ixodid ticks on small ruminants in Greece. Parasitol Res. 2016;115:4673-80.

21. Psaroulaki A, Ragiadakou D, Kouris G, Papadopoulos B, Chaniotis B, Tselentis Y. Ticks, tick-borne rickettsiae, and Coxiella burnetii in the Greek Island of Cephalonia. Ann NY Acad Sci. 2006;1078:389-99.

22. Latrofa MS, Dantas-Torres F, Giannelli A, Otranto D. Molecular detection of tick-borne pathogens in Rhipicephalus sanguineus group ticks. Ticks Tick Borne Dis. 2014:5:943-6.

23. Papa A, Tsioka K, Kontana A, Papadopoulos C, Giadinis N. Bacterial pathogens and endosymbionts in ticks. Ticks Tick-borne Dis. 2017:8:31-5.

24. Manilla G. Acari. Ixodida. In: Fauna d'Italia vol. XXXVI, Edition Calderini. Bologna; 1998.

25. Walker JB, Keirans JE, Horak IG. Genus Rhipicephalus (Acari, Ixodidae). A guide to the brown ticks of the world. Cambridge: Cambridge University Press; 2000. p. 656.
26. Choi YJ, Jang WJ, Ryu JS, Lee SH, Park KH, Paik HS, et al. Spotted fever group and typhus group rickettsioses in humans. South Korea Emerg Infect Dis. 2005;11:237-44

27. Casati S, Sager H, Gern L, Piffaretti JC. Presence of potentially pathogenic Babesia sp. for human in Ixodes ricinus in Switzerland. Ann Agric Environ Med. 2006;13:65-70.

28. Barber RM, Li Q, Diniz PPVP, Porter BF, Breitschwerdt EB, Claiborne MK, et al Evaluation of brain tissue or cerebrospinal fluid with broadly reactive polymerase chain reaction for Ehrlichia, Anaplasma, spotted fever group Rickettsia, Bartonella, and Borrelia species in canine neurological diseases (109 cases). J Vet Intern Med. 2010;24:372-8.

29. Otranto D, Brianti E, Dantas-Torres F, Weigl S, Latrofa MS, Gaglio G, et al. Morphological and molecular data on the dermal microfilariae of a species of Cercopithifilaria from a dog in Sicily. Vet Parasitol. 2011;182:221-9.

30. Inokuma H, Okuda M, Ohno K, Shimoda K, Onishi T. Analysis of the 18S rRNA gene sequence of a Hepatozoon detected in two Japanese dogs. Vet Parasitol. 2002:106:265-71.

31. Larkin MA, Blackshields G, Brown NP, Chenna R, McGettigan PA, McWilliam $H$, et al. Clustal W and Clustal X version 2.0. Bioinformatics. 2007;23:2947-8.

32. Shukullari E, Rapti D, Visser M, Pfister K, Rehbein S. Parasites and vectorborne diseases in client-owned dogs in Albania: infestation with arthropod ectoparasites. Parasitol Res. 2017:116:399-407.

33. Aktas M, Özübek S, Altay K, Ipek ND, Balkaya I, Utuk AE, et al. Molecular detection of tick-borne rickettsial and protozoan pathogens in domestic dogs from Turkey. Parasit Vectors. 2015;8:157.

34. Gray J, Dantas-Torres F, Estrada-Pena A, Levin M. Systematics and ecology of the brown dog tick, Rhipicephalus sanguineus. Ticks Tick Borne Dis. 2013;6:872.

35. Zemtsova GE, Apanaskevich DA, Reeves WK, Hahn M, Snellgrove A, Levin ML. Phylogeography of Rhipicephalus sanguineus sensu lato and its relationships with climatic factors. Exp Appl Acarol. 2016;69:191-203.

36. Hekimoğlu O, Sağlam IK, Özer N, Estrada-Peña A. New molecular data shed light on the global phylogeny and species limits of the Rhipicephalus sanguineus complex. Ticks Tick Borne Dis. 2016:7:798-807.

37. Touloudi A, Valiakos G, Athanasiou LV, Birtsas P, Giannakopoulos A, Papaspyropoulos K, et al. A serosurvey for selected pathogens in Greek European wild boar. Vet Rec Open. 2015;2:e000077.

38. Aktas M. A survey of ixodid tick species and molecular identification of tickborne pathogens. Vet Parasitol. 2014;200:276-83.

39. Maia C, Ferreira A, Nunes M, Vieira ML, Campino L, Cardoso L. Molecular detection of bacterial and parasitic pathogens in hard ticks from Portugal. Ticks Tick Borne Dis. 2014:5:409-14.

40. Murata $T$, Inoue M, Taura Y, Nakama S, Abe H, Fujisaki K. Detection of Hepatozoon canis oocyst from ticks collected from the infected dogs. J Vet Med Sci. 1995:57:111-2.

41. Giannelli A, Lia RP, Annoscia G, Buonavoglia C, Lorusso E, Dantas-Torres F, et al. Rhipicephalus turanicus, a new vector of Hepatozoon canis. Parasitology. 2016;21:1-8

42. Duh D, Punda-Polic V, Trilar T, Petrovec M, Bradaric N, Avsic-Zupanc T. Molecular identification of Rickettsia felis-like bacteria in Haemaphysalis sulcata ticks collected from domestic animals in southern Croatia. Ann NY Acad Sci. 2006;1078:347-51.

43. Marquez FJ. Spotted fever group Rickettsia in ticks from southeastern Spain natural parks. Exp Appl Acarol. 2008;45:185-94

44. Ioannou I, Sandalakis V, Kassinis N, Chochlakis D, Papadopoulos B, Loukaides $F$, et al. Tick-borne bacteria in mouflons and their ectoparasites in Cyprus. J Wildl Dis. 2011;47:300-6

45. Matsumoto K, Ogawa M, Brouqui P, Raoult D, Parola P. Transmission of Rickettsia massiliae in the tick Rhipicephalus turanicus. Med Vet Entomol. 2005;19:263-70.

46. Otranto D, Dantas-Torres F, Giannelli A, Latrofa MS, Cascio A, Cazzin S, et al. Ticks infesting humans in Italy and associated pathogens. Parasit Vectors. 2014;7:328.

47. Papa A, Xanthopoulou K, Kotriotsiou T, Papaioakim M, Sotiraki S, Chaligiannis I, et al. Rickettsia species in human-parasitizing ticks in Greece. Trans R Soc Trop Med Hyg. 2016;110:299-304.

48. Solano-Gallego L, Baneth G. Babesiosis in dogs and cats - expanding parasitological and clinical spectra. Vet Parasitol. 2011;181:48-60.

49. Sainz Á, Roura X, Miró G, Estrada-Peña A, Kohn B, Harrus S, et al. Guideline for veterinary practitioners on canine ehrlichiosis and anaplasmosis in Europe. Parasit Vectors. 2015:8:75 